$$
\begin{aligned}
& \text { SONF-881248 } \\
& \text { Rern: }
\end{aligned}
$$

Ait is 0 b 1389

LA-UR--89-1095

DE89 009247

TITLE A NEW FIELD EXPERIMENT IN THE GREENIAND ICE CAP TO TEST NEWTON'S INVERSE SQCARE LAW

\author{
AUTHOA,SI MARK E. ANDER ESS-3 \\ MARK $=$ ZUMBERGE \\ TED 1 'ZENHISFR \\ ROBERT L. PARKER \\ CARLOS L. V. AIKEN
}

MICHAEL R. GORMAN

MICHAEL MARTIS NIETO :-

JOHN R. FERGUSON

GECRGE A. MCMECHAN

SUBMITTED TO PROCEEDINGS OF THE TEXAS REJATIVITY CONFERENCE

\title{
IISC'I,AIMER
}

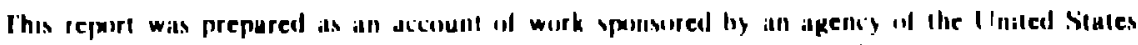

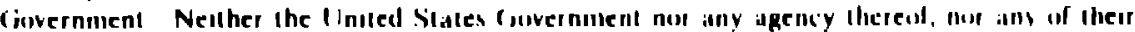

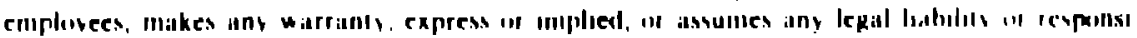

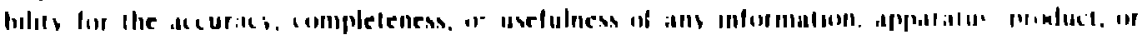

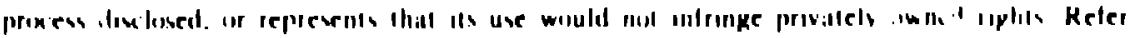

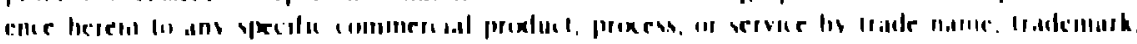

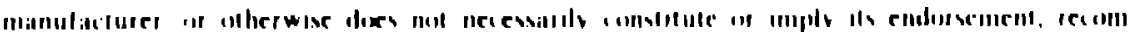

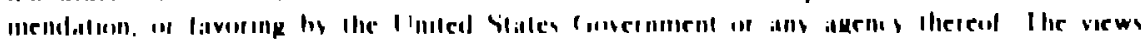

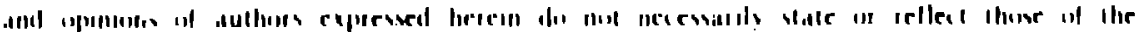

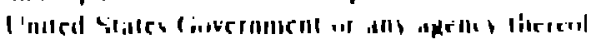

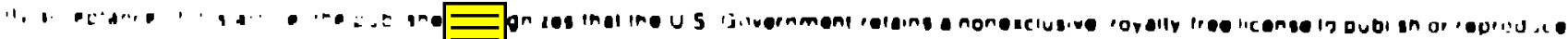

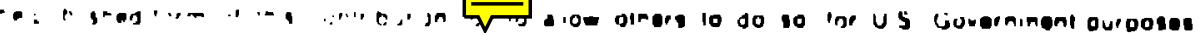

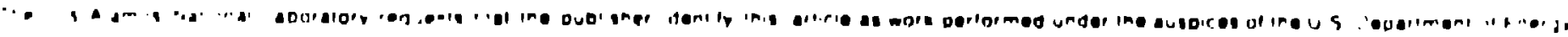

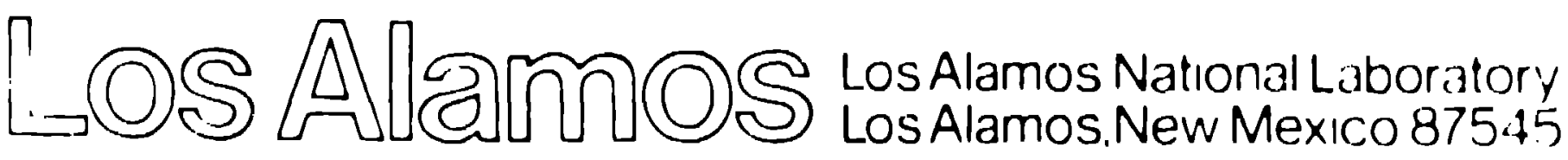

(

$\therefore \quad, 1, \ldots$

MASTFR

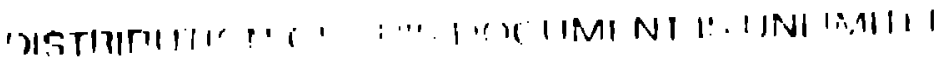




\section{A NEW FIELD EXPERIMENT IN THE GREENLAND ICE CAP TO TEST NEWTON'S INVERSE SQUARE LAW}

by

Mark E. Ander ${ }^{a}$

Mark A. Zumberge

Ted Lautzenhiser

Robert L. Parker

CARLOS L. V. AIKEN

Michael R. Gorman'

Michael Martin Nieto

John F. Ferquson

George A. McMechand

\footnotetext{
antversity of California, Los Alamos National Lab, I.os Alamos, NM 87545

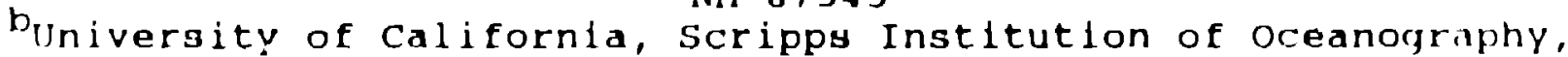
La Jolla, CA 92093

${ }^{C}$ Amoco Production Co., P. O. Box 3385, Tulsa, OK 74102

University of Texas at Dallas, Richardson, 'Tx 75083

Cambridge University, Scott Polar Research Institute, Cambridye ('H2 $1 \mathrm{EK}$, Lingland
} 


\begin{abstract}
Abatract
A geophysical experiment was conducted in a 2-km-deep hole in the Greenland ice cap at depths between $213 \mathrm{~m}$ and $1673 \mathrm{~m}$ to test for possible violations of Newton's inverse-square law. A detailed ice-sounding radar survey was carried out to $5 \mathrm{~km}$ from the hole and merged with regional airborne radar data tc define the basement interface. Highly accurate gravity measurements were carried out to $15 \mathrm{~km}$ from the hole to detect lateral density changes in the bedrock. The measurements were controlled with very accurate satellite and conventional positioning techniques. The basement interface model was input into a Newtonian computation to correct the observed gravity for known earth. structure resulting in an anomalous gravity gradient of +3.87 mGal. A 3 dimensional ldeal body aralysis of the surface and borehole gravity data provided a means of bounding all possibie Newtonian solutions for lateral density varlation below the ice. Solutions with regional gravity offsets $\geq 10 \mathrm{mGal}$ and density contrasts $\leq 0.30 \mathrm{~g} / \mathrm{cm}^{3}$ are possible. We cannot unambiquously attribute the anomalous gradient to a breakdown of Newtonian gravity because there remains the possibility it is due to unexpected geologlcal features in the rock below the ice.
\end{abstract}


Recent experimental evidence suggests that Newton's law of gravity may not be precise $(1,2)$. There are modern theories of quantum gravity that, in their attempts to unify gravity with other forces of nature, predict non-Newtonian gravitational forces that could have ranges on the order of $10^{2}-10^{5} \mathrm{~m}$. If they exist, these forces would be apparent as violations of Newton's inverse square law. A geophysical experiment was carried out to search for possible finite-range, non-Newtonian gravity over depths of 213-1673 $\mathrm{m}$ in the glacial ice of the Greenland ice cap. The principal reason for this choice of experimental site is that a hole drilled through the ice cap already existed, and the uniformity of the ice eliminates one of the major sources of uncertairty arlsing in the first of earlier studies ${ }^{2}$, namely, the heterogeneity of the rocks through which a mineshaft or cirlll hole passes. Our observations were made in the summer of 1987 at Dye 3, Greenland, in the $2033 \mathrm{~m}$ deep borehole, which reached the basement rock. The site $1 \mathrm{~s} 60 \mathrm{~km}$ south of the Arctic circle, 125 $\mathrm{km}$ inland from Greenland's east coast, and at $2560 \mathrm{~m}$ elevation (Fig. 1).

The general configuration of the experiment is presented in Fiqure 2. The Newtonian prediction of the gravity profile in the borehole, based on a density model of the lice and the topographic relief of the bedrock and lce surface developed from geop'iystial moasurements, was compareci with measured values. IIfferences in gravity, 9 , were moasured at sevoral deptha, $z$, ind modoled by: 


$$
g_{m}(z) \approx r z-4 \pi G \rho_{i} z+g_{r}(z) .
$$

where $\gamma$ is the theoretical free-air gravity gradient, $G$ is the Newtonian gravitational constant as determined in laboratory experiments, $\rho_{i}$ is the ice density, and $g_{r}$ is a correction to the gravity differences based on the attraction of the sub-ice terrain. (The effect of the ice-surface topography is negligible.) Although Eq. (1) is adequate within the uncertainties of our experiment, a more exact expression ${ }^{4}$ which accounts for a vertical change in density, and the earth's ellipticity was used in the calculations. The gravity dnomaly, ganom, is defined as the difference between the modeled gravity, $g_{m}$, and the observed gravity in the borehole, gobs'

$$
g_{\text {anom }}=g_{\text {obs }}(z)-g_{m}(z) \text {. }
$$

The steps taken to obtain the experimental observations and model zalculations will be described. The results are shown in Table 1. The uncertainties in this table include contributiors from the measurements themselves and from imperfect knowledge of the ice density and the terrain, with the latter effect dominating. They do rot. reflect an ignorance of the density inhomogeneities in the underlying roik.

An accuracy of one part in one thousand was determined to be necessary in all measurements in order to provide the gravity sufficlently accurately to detect the theoretically predicted leviatlons in Newtonian gravity. Ihis would require not only iccurate gravity measurements but also accurate locations of ill 
observations, because of the effect of variation of gravity with location, especially elevation.

In order to insure an ultimate accuracy of iess than 0.03 mGal, the borehole gravity meter was calibrated in Canada and Alaska over the range of gravity valuss expected in the Dye 3 borehole by comparison with the readings of an absolute gravity meter ${ }^{5}$, resulting in uncertainties in calibration less than 0.03 mGal in the borehole.

The borehole in Greenland is not vertical, so its trajectory was obtained from downhole inclinometers. The wireline to be used for lowering the gravimeter down the hole, ias callbrated in a $1520 \mathrm{~m}$ mine shaft at the Consolidated Sliver mine in Idaho by comparison with a laser geodimeter 5 before and after the Greenland experimenta and reeulted in measured depthe to an accuracy of about 1 part in $10^{4}$.

Approximately 100 gravity observations were made in the borehole distributed over $B$ stations placed at 183 m intervals. The uncertainty in the gravity measurement at each derth is estlmated to be $0.05 \mathrm{mGal}$. A surface gravity survey was performed with Lacoste-Romberg relative gravity meters. Tine reglon covered was $32 \mathrm{~km}$ in diameter and consisted of 25 situs on three rings and at the center. Each site wrs occupled four times (variously by two different observera) with four gravity meters. filevations for the sites were obtained with a combination of 
first-order optical leveling and satellite observations with the Global positioning system. After corrections (to be described below) the gravity values are used to provide further constraints on possible sub-ice density variations.

The properties of ice have been extensively studied; samples from Dye 3 have been analyzed in detail 6 and densities were calculated to an accuracy to 7 parts in $10^{4}$ over the dapth range of our experiment 5 .

Additional gravity gradients are created by the undulations of the basement rock; it is therefore important to map the ice thickness for a considerable distance around the site of the experiment. Airborne and ground ice-penetrating radar surveys had previously been made in the vicinity of the site?, providing moderately accurate coverage to a distance of more than $60 \mathrm{~km}$. A more detailed surface radar survey was completed within a $5 \mathrm{~km}$ radius of the Dye site using the scott Polar Research Institute radar system ${ }^{5}$ (Fig. 3). The bedrock topography map was constructed from the radar travel-times by a three-dimensional migration algorithm (recorded along 124 radial lines for a total of about 42,000 soundings). The resultant map is defined by a grid at a $125 \mathrm{~m}$ interval with a vertical uncertainty of $\leq 5 \mathrm{~m}$ over 70 of the area. In a few exceptional places far from the borehole, where reflections were very weak, the uncertainty rose to $50 \mathrm{~m}$. Ice thlckness estimates range, with position, from approximately $1800 \mathrm{~m}$ to $2100 \mathrm{~m}$ and $1 \mathrm{~s}$ in general aqreement with 
previous regional surveys. The ice surface topography was also mapped, out to $5 \mathrm{~km}$ from the borehole, to an accuracy of about 1 m using an electronic distance meter and theodolite.

The gravitational effect of bedrock topography (the terrain correction) was computed at each gravity observation point, both on the ice surface and in the borehole, using two different techniques. The bedrock density was taken as $2.70 \mathrm{~g} / \mathrm{cm}^{3}$, as given by Jezek et $a .^{8}$. The two calculations agreed to within $0.01 \mathrm{mGal}$ at locations down the hole. Imperfect knowledge of the terrain was the largest component of the gravity corrections.

After all these conventional adjustments are applied, there remains an unexplained gravity difference of $3.87 \pm 0.36 \mathrm{lnGal}$ between the grasity value at a depth of $213 \mathrm{~m}$ and at $673 \mathrm{~m}$.

The rock beneath the ice has been treated as homogeneous. However, density variations in the rock generally produce vertical gravity gradients and geological studies of the coastal regions of Greenland show that maflc intrusions with densities from 2.8 to $3.0 \mathrm{~g} / \mathrm{cm}^{3}$ are found within the metamorphic basement and occupy a few percent of the exposed basement rock ${ }^{9}$. The surface gravity map (Fig. 4) reveals anomalieg within our network that could be due to such masses.

To demonstrate unambiguously the inadequacy of a purely Newtonian explanation, one mist show that no reasonable density 
variation in the basement can produce the observed anomalous borehole gravity profile without conflicting with the surface gravity survey data. It is well known that even complete gravity information outside a body cannot uniquely determine the internal density structure. However, the theory of ideal bodies 10 leads to a rigorous calculation of the smallest possible density contrast mathematically consistent with a finite number of gravity observations. If such a calculation showed that a geologically unacceptable density contrast was required to produce the measure gravity values, the case for a modification of Newton's law of gravity would be made.

The smallest density contrast was found subject to a specified weighted sum of the squared misfit to the observations and their associated errors. All 25 surface values and 8 borehole values were used. The problem was solved approximately with a quadratic programming algorithm, which constructs a block misdel of the density distribution. It is easily shown that the density contrast zausing the Chi squared-per-degree-of-freedorn value to achieve a specified value is the smallest possible density contrast consistent with that misfit. Thus, by varying the density we can find the least density contrast within the basement necessary to reproduce the observations as measured by the size of the misfit functional.

All the gravity measurements are relative, so that, in principle the same arbitrary constant may be added to each one. 
To avoid the necessity of huge anomalous masses whose presence would be inconsistent with geological considerations, an offset is allowed as a parameter in the $f i t$. Since the gravity survey reveals variations in the corrected surface gravity of up to 10 mGal, values on this order for the arbitrary constant are acceptable, but values several times larger would be difficult to justify.

The bound on the density contrast and the constant gravity offset was systematically varied and the results displayed as the smallest possible misfit to the observations. The squared misfits were ncralizal by the number of observations (Chisquared-per-degree-of-freedom, see Fig.5). The unit contour line defines a good fit to the data, and a good fit can be obtained for large but plausible density contrasts and acceptable offset values. For example, the mass distribution depicted in Figure 6 , generated by the ideal-body code, has a density contrast of 0.3 $\mathrm{gm} / \mathrm{Cm}^{3}$ (larger than this may be geologically unreasonable for Greenland) and a regional of fset of $10 \mathrm{mGal}$. The mass distribution simultaneously fits the surface and borehole gravity observations. The intrusive bodies represent a larger amount of mass than would be expected based on geologic maps of the Greenland coast, where the rock is exposed ${ }^{9}$. Further, these bodies fit the surface data alone and need only slight alteration to fit the borehole daita as well. 
The distribution found is not meant to be interpreted as the actual one in the earth. It is representative of mathematically possible solutions for the density lower bound. The fundamental nonuniqueness of the inverse gravimetric problem makes it impossible to identify the actual density distributions respcnsible for the gravity observations.

The above indicates that any complete analysis of geophysical experiments searching for non-Newtonian gravity should include a careful estimate of the ability of small density contrasts to generate substantial vertical gravity gradients. Future experiments should be designed with this approach in order to quantify the gravitational contribution of geologic heterogeneity. The best experiment will be one in which the anomalous gravity demonstrably exceeds the quantifiable geologic "noise".

In conclusion, an anomalous gravity gradient was found that could be taken as evidence for non-Newtonlan gravity. This possibility was tested by using regional gravity offset and density contrast is parameters in an ideal-body analysis, which found tinat the data can be flt with a Newtonian gravity model if one allows large mafic intrusions in the bedrock and a significant regional gravity offset. These findings could be further lested by performing other geophysical surveys in the region, such as aeromagnetic, to define the extent of the intrusives. 
Acknowledgements. This research was supported by the National Science Foundation, Los Alamos National Laboratory under the auspices of the Department of Energy, Amoco Production Company, Institute of Geophysics and Planetary Physics, the Air Force Geophysics Laboratory, and The University cf Texas at Dallas Ge physical Consortium.

\section{REFERENCES}

IGOLDMAN, T., R. J. HUGHES, and M. M. NIETO. 1986. Phys. Lett. 171B:217, and references therein.

${ }^{2}$ HOLDING, S. C., F. D. STACEY, and G. J. TUCK. 1986. Phys. Rev. D3 3:3487, and references therein.

${ }^{3}$ ECKHART, D. H., C. JEKEILI, A. R. LAZARENICZ, A. J. ROMAIDES, and R. W. SANDS. 1988. Phys. Rev. Lett. 60:2567. ${ }^{4}$ STACEY, S. F. D., G. J. TUCK, G. I. MOORE, S. C. HOLDING, A. R. Maher, D. MORRIS. 1981. Phys. Rev. D 23:1683; A. Dahlen. 1982. Phys. Rev. D25:1735.

${ }^{5}$ This and other aspects of the experiment will be discussed elsewhere, including: ANDER, M. E., W. KERR, C. L. V. AIKEN, G. C. GLOVER, and M. A. ZUMBERGE. Submitted 1988. Geophysics; GORMAN, M. R., A. P. R. COOPFR, M. E. ANDER, C. L. V. AIKEN, E. FISHER, and G. A. MCMECHAN. Submitted 1988. J. Geophys. Res., FISHER, E., G. MCMECHAN, M. GORMAN, A. P. R. COOPER, C. L. V. AIKEN, M. E. ANDER, and M. A. ZIJMBERGE. In pross 1989. J. Geophys. Res.

GIANGWAY JR., C. C., H. OFGCHGER, and W. DANGSGAARD, Fiditor: 1985, Greenland Icc core: Geophysics, Geochemitstry, and tho 
Environment, Geophysical Monograph 33, American jeophysical

Union, Washington, D. C.

7OVERgAard, S., 1978. Radio Echo Sounding in Greenland, Data

Catalog 1978. Technical University of Denmark; OVERGAARD, S. and N. S. GUNDESTRUP, ref. 6, p. 49; GUNDESTRUP, N. S., private comm. ${ }^{8}$ JEZEK, K. C., E. A. ROELOFFs, and L. L. GREISCHAR, in ref. $6, p$. 105; JEZEK, K. C., private comm.

${ }^{9}$ WINDLEY, B. F. 1984. The Evolving continents, second Ed. Niley, New York.

10PARKER, R. L. 1974. Geophysics 39:644; Geophys. J. Roy. Astr. SOC. 12:315. 1975; ANDER, M. E. and S. P. HUESTIS. 1988. Geophysics $52: 1265$.

11 PARKER, R. L. 1988. EOS 69:1046. 
TABLE 1

\begin{tabular}{crrrrrrrr}
$z$ & \multicolumn{1}{c}{$\Delta z$} & \multicolumn{1}{c}{$g_{\Delta z}$} & \multicolumn{1}{c}{$g_{\text {ice }}$} & \multicolumn{1}{c}{$g_{\mathrm{r}}$} & \multicolumn{1}{c}{$g_{\mathrm{m}}$} & \multicolumn{1}{c}{$g_{\text {obs }}$} & \multicolumn{1}{c}{$g_{\text {obs }}-g_{\mathrm{m}}$} & ${ }^{\sigma_{g}}$ \\
212.22 & 0.00 & 0.00 & 0.00 & 0.00 & 0.00 & 0.00 & 0.00 & 0.26 \\
395.12 & 182.90 & 56.37 & -14.06 & -0.25 & 42.06 & 42.39 & 0.33 & 0.25 \\
579.00 & 365.78 & 112.74 & -28.13 & -0.52 & 84.06 & 84.72 & 0.63 & 0.23 \\
761.83 & 547.61 & 169.09 & -42.21 & -0.82 & 126.06 & 127.13 & 1.07 & 0.20 \\
344.63 & 731.41 & 225.45 & -56.31 & -1.14 & 168.00 & 169.48 & 1.48 & 0.19 \\
1309.40 & 1096.18 & 337.91 & -84.44 & -1.92 & 251.55 & 254.10 & 2.55 & 0.15 \\
1491.18 & 1277.96 & 393.97 & -98.47 & -2.40 & 293.10 & 296.32 & 3.22 & 0.13 \\
2673.23 & 1460.01 & 450.11 & -112.52 & -2.95 & 334.64 & 338.51 & 3.87 & 0.25
\end{tabular}

Table 1. This contains the absolute observation depths, $z$; the depths relative to the shallowest observation point, $\Delta z$; the theoretical free-air term, $r \Delta z$; the effect due to the ice (approximately the second term in Eq. (1)), gice; the attraction of the sub-ice terrain, $g_{r}$; the theoretical gravity differences, $g_{m}=r \Delta z+g_{1 c e}+g_{r} ;$ the observed gravity differences, $g_{o b s}$; the anomalies, $g_{0 b s}-g_{m}$; and the uncertalnties, $o_{g}$ (Note: $1 \mathrm{mGa}$ ) $10^{-3} \mathrm{~cm} / \mathrm{s}^{2}$.) The modeled and observed values are of them both zero at $z=213.22 \mathrm{~m}$, which is permitted since all the gravity observations are relative. All distances are in meters and all gravity values are in mGal. 
FIGURE CAPTIONS

Fig. 1. Location of Greenland Experiment at Dye-3 Distant Early Warning Radar station.

Fig. 2. Diagramatic model of the earth at the Dye-3 well site. Approximate values of deptiss and densities are shown.

Fig. 3. 3 Dimensional view of detailed basement topography from radar soundings at Dye-3.

Fig. 4. Complete Bouguer gravity anomaly map of the vicinity surrounding the Dye-3 study area (which is located at 0,0 ). Fig. 5. A contour map of $x^{2} /(33$; obtained wy fitting the 33 gravity station measurements with an ideal body of density cortrast $\Delta \rho$ located at and below the rock-ice interface, in a field with regional gravity offset, $\Delta g_{0}$. The specific case of $\Delta \rho$ $=0.30 \mathrm{~g} / \mathrm{cm}^{3}$ and $\Lambda g_{0}=20 \mathrm{mGal}$ is exhlbited in Fig. 2 .

Fig. 6. The plan view, at the rock-ice interface, of the ideal body with density contrast $\Delta \rho=0.30 \mathrm{~g} / \mathrm{cm}^{3}$, in a regional of fset field of $\Delta g_{0}=10 \mathrm{mGal}$, which can model the gravity observations. The vertical dimension of each piece of the idaal body is roughly the same as its horizontal dimension. The triangles denote the locations of the gravity measurements on the surface. 


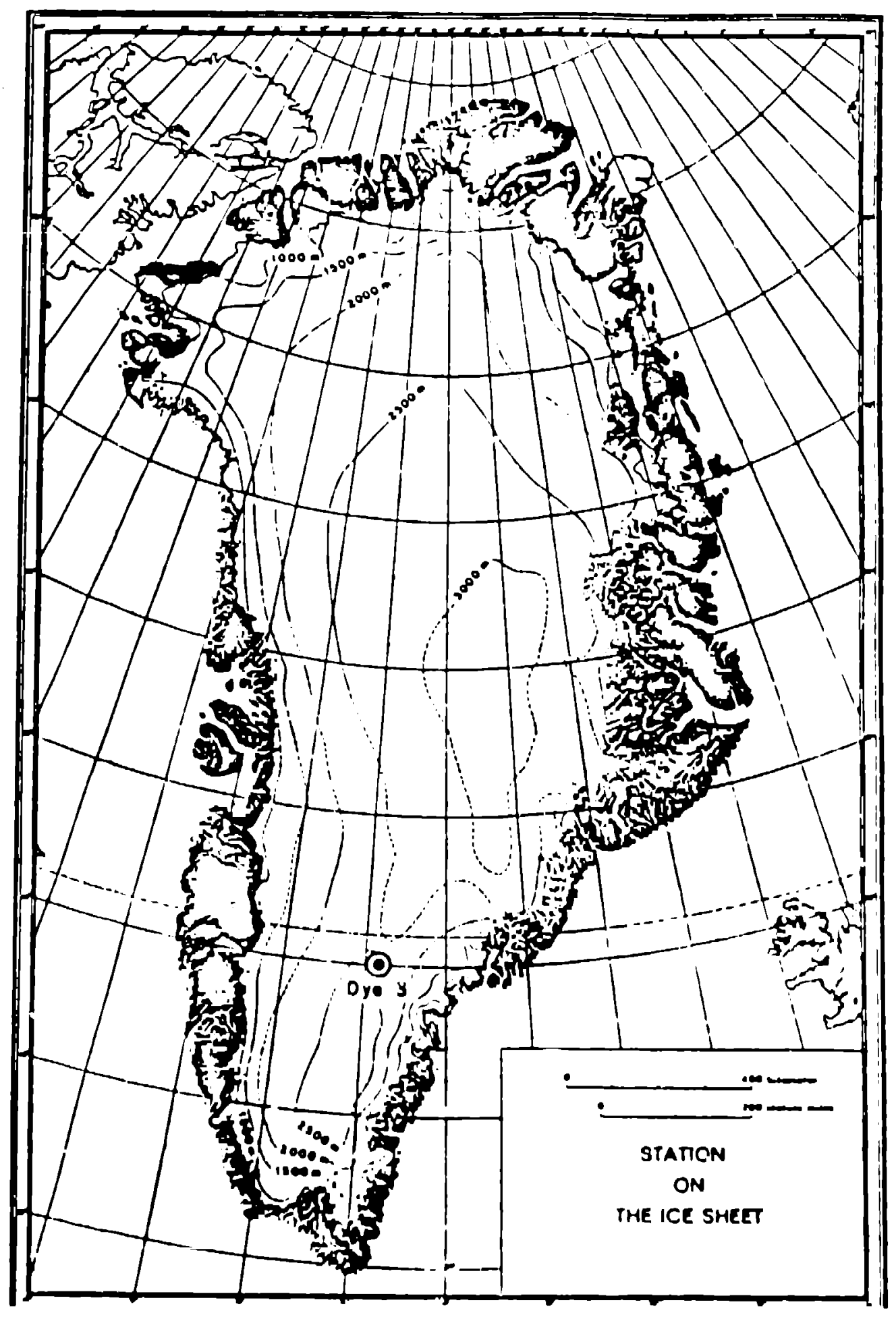




\section{Dye 3, Greenland}

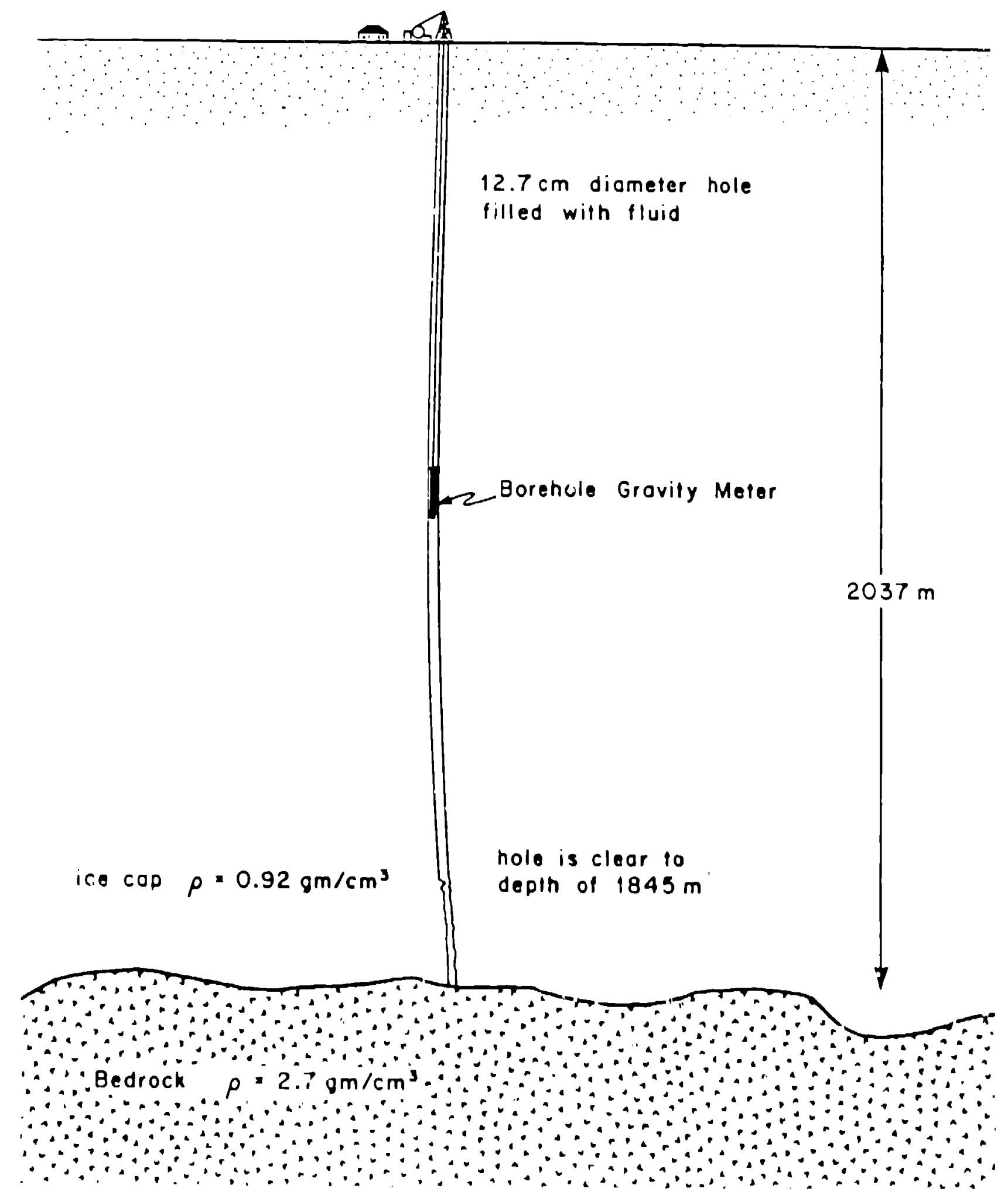


Elevation of basement about mean depth of 2004.: 1

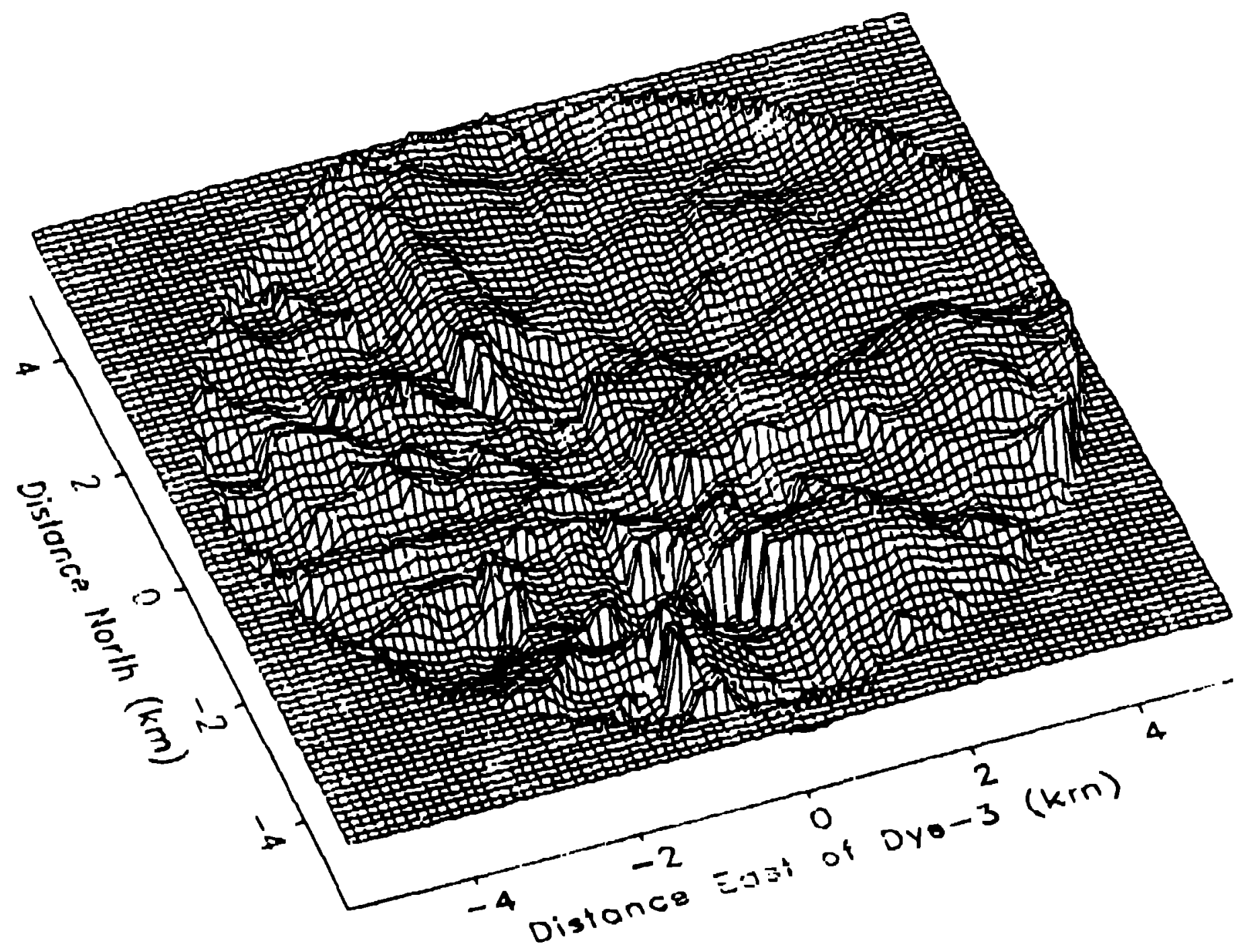




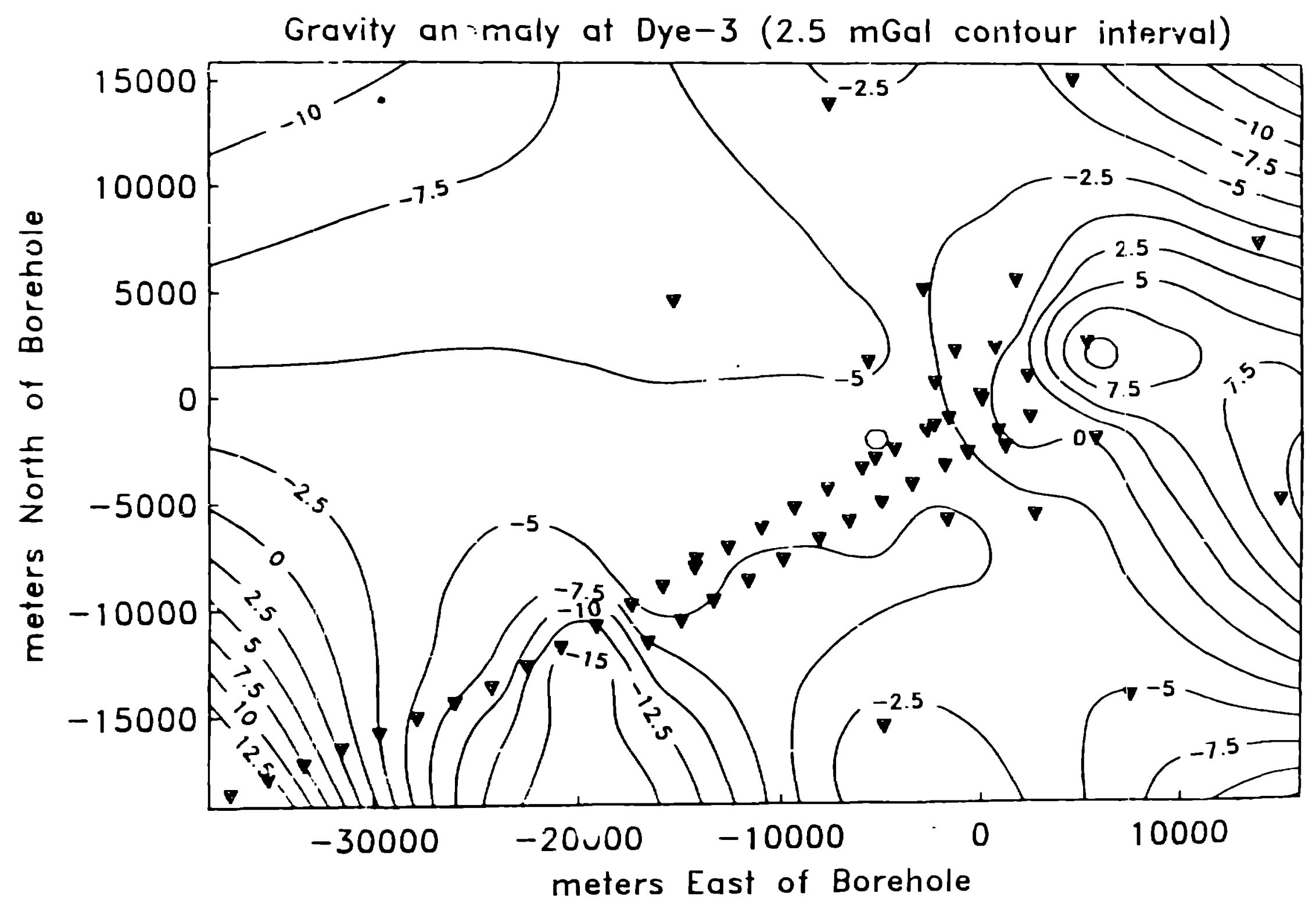




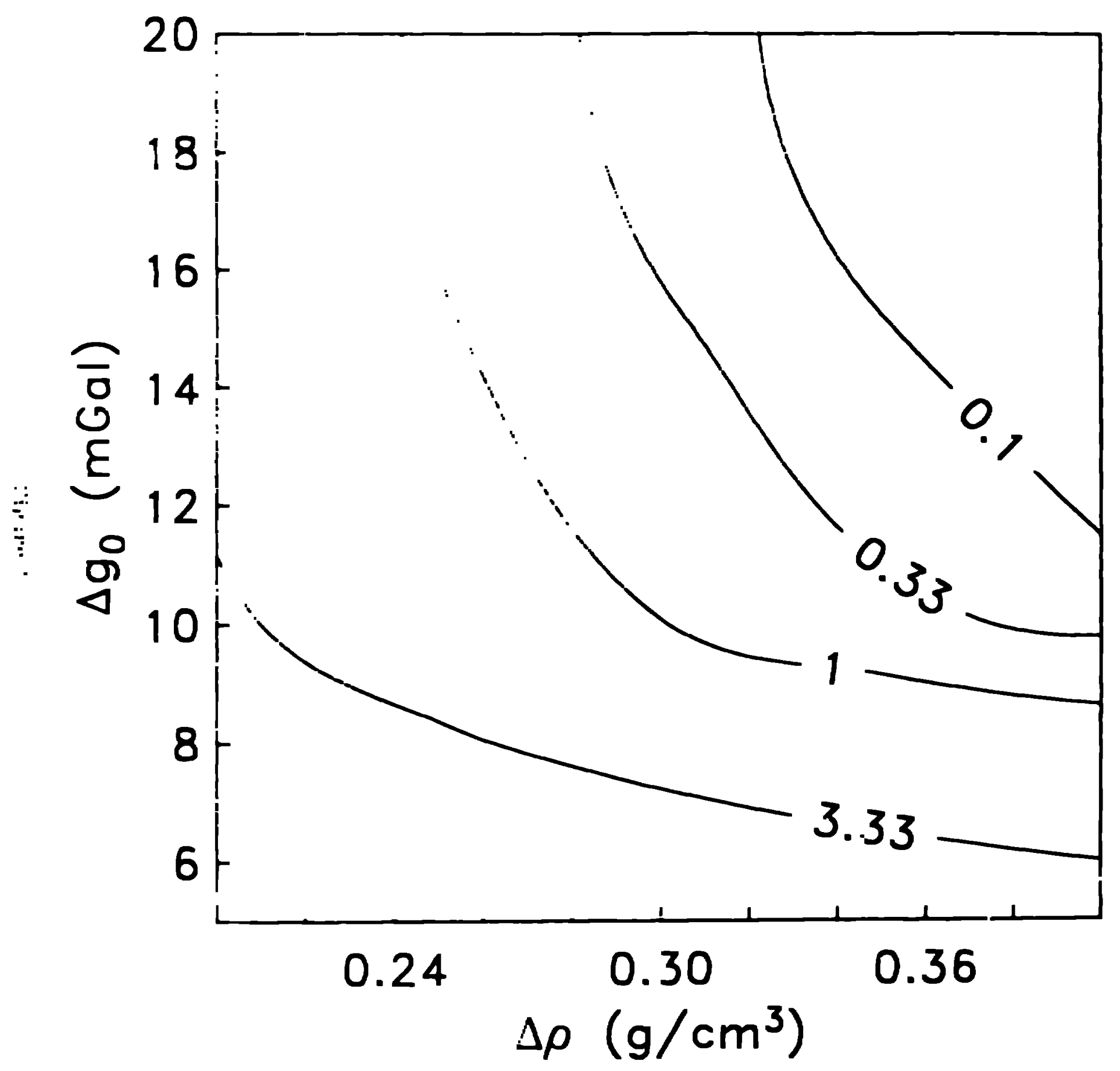




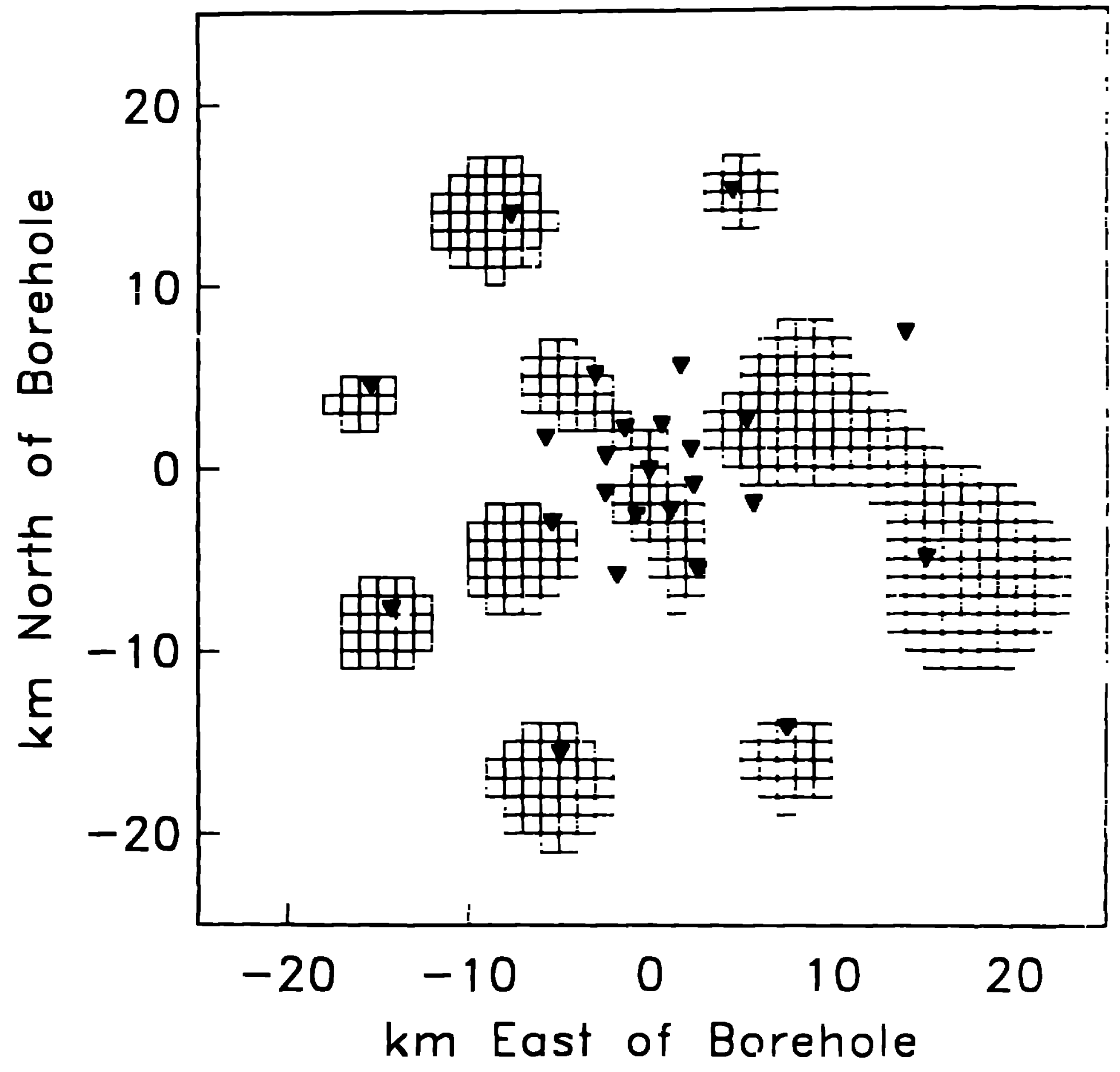

